\title{
Improved Acetone-Butanol-Ethanol (ABE) Solution Analysis Using HPLC: Chromatograph Spectrum Deconvolution Using Asymmetric Gaussian Fit
}

\author{
Niloofar Abdehagh1, Mehran Bagheri' ${ }^{2}$, Fatma Handan Tezel${ }^{1}$, Jules Thibault ${ }^{*}$ \\ ${ }^{1}$ Chemical and Biological Engineering Department, University of Ottawa, Ottawa, Canada \\ ${ }^{2}$ Department of Physics, University of Ottawa, Ottawa, Canada \\ Email: *Jules.Thibault@uottawa.ca
}

Received 7 September 2014; revised 23 October 2014; accepted 9 November 2014

Copyright (C) 2014 by authors and Scientific Research Publishing Inc.

This work is licensed under the Creative Commons Attribution International License (CC BY).

http://creativecommons.org/licenses/by/4.0/

(c) (i) Open Access

\begin{abstract}
Currently, the analysis of acetone-butanol-ethanol (ABE) broths is performed using both High Performance Liquid Chromatography (HPLC) and Gas Chromatography (GC) for each sample since GC cannot be used in quantifying sugars and HPLC methods are not yet efficient enough to detect all components separately. In this study, a novel method was developed to quantify all main components present in ABE model solutions (acetone, butanol, ethanol, butyric acid, acetic acid, glucose and xylose) using only HPLC. Although the HPLC operating conditions were optimized to obtain the best possible resolution in HPLC chromatograms, it was observed that the peaks for butyric acid, acetone and ethanol overlapped. The same trend was observed for glucose and xylose. Using the asymmetric Gaussian fit, a program was written in MATLAB to detect the overlapped peaks, deconvolute them and calculate the area of each separated peak. The concentrations of each component were then calculated using the areas and the calibration curves for each component. Experimental results show that this method works well for the ABE model solutions and can be used to quantify all components in the solution when there are some overlapped peaks in the HPLC chromatograms.
\end{abstract}

\section{Keywords}

High Performance Liquid Chromatography, Overlapped Peaks, Deconvolution, ABE Broths Analysis, Biobutanol

\footnotetext{
*Corresponding author.
}

How to cite this paper: Abdehagh, N., Bagheri, M., Tezel, F.H. and Thibault, J. (2014) Improved Acetone-Butanol-Ethanol (ABE) Solution Analysis Using HPLC: Chromatograph Spectrum Deconvolution Using Asymmetric Gaussian Fit. American Journal of Analytical Chemistry, 5, 1078-1089. http://dx.doi.org/10.4236/ajac.2014.516115 


\section{Introduction}

Due to environmental challenges and problems associated with fossil fuels such as depletion of resources, high cost and political instability in oil-producing countries, one of industrialists' and scientists' main concerns is to produce fuels from sustainable resources. Amongst the existing options, biofuels have attracted significant attention because their production methods are more environmentally friendly. Biofuels such as bioethanol and biobutanol have shown to be promising alternatives to fossil fuel. Butanol production via fermentation is currently the subject of intense research because it is reputed as one of the best renewable alternative biofuels to replace gasoline. Biobutanol has more favorable characteristics in comparison to other biofuels such as bioethanol. Butanol has a net heat of combustion (NHOC) close to gasoline; it is less hazardous to handle due to its lower vapor pressure and volatility, and it can be blended with gasoline in any proportion and be used in existing car engines without any modifications [1]-[9]. It is however limited by its low final concentration due to product inhibition. Acetone-butanol-ethanol (ABE) fermentation is the most studied bioproduction method to produce butanol. Clostridia species are the most common microorganisms used for this fermentation process [9]-[11].

In ABE fermentation, a number of products are present in the fermentation broth including acetone, butanol, ethanol, acetic acid, butyric acid and sugars (glucose and xylose). To be able to characterize the fermentation process (yield, productivity and concentration of the product and each of the byproducts), precise quantification of all components is required. High performance liquid chromatography (HPLC) and gas chromatography (GC) are used to quantify the components present in ABE fermentation broths. However, the separation and quantification of all the different components in the fermentation broth have not been successfully achieved using only one of these two instruments. Using simultaneously both instruments increases the capital cost and time required to perform an analysis.

Since GC cannot be used to detect sugars in the samples, it is required to use HPLC or other techniques when the solvents and organic compounds are detected by GC. Various GC operating methods and columns (packed and capillary) such as fused silica (Stabilwax-DA), Innowax 19091N-133 (Agilent Technologies Inc.), capillary column SE-30 (Lanzhou Institute of Chemical Physics) and Porapak Q (80/100) (ALLTECH) have been used to measure the concentration of acetone, butanol, ethanol, butyric acid and acetic acid in the fermentation broths [12]-[16]. However, in all studies HPLC was required for quantifying sugars. HPLC cannot also be used straightforwardly for measuring the concentration of all components since butyric acid, acetone and ethanol have approximately the same retention time in HPLC chromatograms for most of the HPLC columns used to determine the concentration of alcohols and other components of the fermentation broths. Different HPLC methods (various column temperatures, mobile phase flow rates and different columns) have also been investigated to analyze solvents, organic acids and sugars present in the ABE fermentation broth. Although there are some studies where different HPLC methods were investigated, a precise method with specific methodology to quantify all desired components with a reasonable resolution does not yet exist. Moreover, there is still some controversy among the different results published in the literature. Aminex HPX-87H (300 × $7.8 \mathrm{~mm}$, Bio-Rad) is one of the most common HPLC columns used to quantify the ABE fermentation broth compounds [17]-[22].

Buday et al. [17] investigated different column temperatures to find the optimum temperature for this column to achieve an adequate separation of ethanol, acetone and butyric acid peaks. They found that at $60^{\circ} \mathrm{C}$ ethanol and acetone peaks had exactly the same retention time and, by decreasing the temperature to a sub-ambient temperature of $14^{\circ} \mathrm{C}$, the peaks were separated but some overlap for acetone and butyric acid was still observed. Wang et al. [18] used the same column at $15^{\circ} \mathrm{C}$ to detect all $\mathrm{ABE}$ fermentation broth components and they have found that this column worked only when it was completely clean and needed to be replaced after a few months when the chromatograms showed low resolutions. Finch et al. [19] also used the Aminex HPX-87H HPLC column at $30^{\circ} \mathrm{C}$ to quantify the components present in $\mathrm{ABE}$ fermentation broths. However, in their paper they have not mentioned acetone as one of the components detected by this column and it seems they have measured the acetone concentration using another method. Cho et al. [20] also used the same HPLC column to investigate the effect of acetic and formic acid on ABE production in ABE fermentation. Although the same microorganism (Clostridium acetobutylicum) was used to produce butanol, they did not measure butyric acid in the fermentation broth as one of the intermediate products.

In a recent study, Kumar et al. [21] developed a methodology to quantify all of the ABE fermentation broth components using the Aminex HPX-87H HPLC column at $65^{\circ} \mathrm{C}$. They used a mathematical relationship between the areas and the heights of the peaks to predict the area under the overlapped peaks of acetone and butyric acid assuming the peaks as Gaussian curves. Although they obtained fairly precise results at low concen- 
trations of ABE compounds (up to $5 \mathrm{~g} / \mathrm{L}$ ), the underlying Gaussian curve assumption may not always be valid since the peaks in HPLC chromatograms could be asymmetric Gaussian peaks. Also, since the overlapped peaks are the summation of the two peaks, the height of each separated peak is not the same as the height of the same peak when a significant overlap with other peaks exists. The assumption used in their study would be valid when the widths of the peaks are equal; however, each peak in a HPLC chromatogram has usually a unique width. Therefore, if any of these assumptions are not valid, the correlation used to measure the concentrations of the components with close retention times (RT) having overlapped peaks would lead to incorrect concentrations [21]. Eurokat H Vertex column $(300 \times 8 \mathrm{~mm}, 10 \mu \mathrm{m}$, KNAUER, Germany) is another HPLC column used for ABE fermentation broth analysis. Setlhaku et al. [23] [24] used this column to quantify the components present in ABE fermentation broths. This column allows performing the HPLC at higher temperatures instead of sub-ambient temperature whereas Amines HPX-87H column for best performance could only operate at low temperatures. Setlhaku et al. [24] used this column at $80^{\circ} \mathrm{C}$ and observed that although the RT of ethanol peak was different than the peaks of butyric acid and acetone, there was still a partial overlap between butyric acid and acetone peaks.

In the present study, a novel methodology is developed and used to quantify the main components present in ABE fermentation broths by HPLC using the asymmetric Gaussian fit to deconvolute the overlapped peaks and determine the coefficients of the equations representing separate peaks in order to calculate the area and subsequently the concentration of each component. This proposed method was used to quantify the pure component samples as well as the multi component samples to verify its accuracy and precision.

\section{Materials and Methods}

\subsection{Materials}

To prepare samples, n-butanol (99\% pure, Acros), acetone (95\% pure, Acros), n-butyric acid (99\% pure, Acros) and 99\% pure ethanol, acetic acid, glucose and xylose, obtained from Fisher Scientific (Fisher Scientific Co., Fair Lawn, NJ, USA), were used. Deionized distilled water was used to prepare all model solutions. The software used to operate the HPLC was Breeze (Waters, Canada) and the mobile phase used was $0.01 \mathrm{~N}$ sulfuric acid with a flow rate of $0.8 \mathrm{~mL} / \mathrm{min}$. The temperature of the column was kept at $85^{\circ} \mathrm{C}$.

\subsection{Equipment Specifications}

The HPLC used in this study was purchased from Waters, Canada. The detector, pump and autosampler were Refractive Index Detector (Waters 2414), Isocratic HPLC pump (Waters 1515) and Autosampler (Waters 717 plus), respectively. To heat the column to the desired temperature, an external column heater was used. The column used in this study to detect ABE solutions was the Vertex column (300 $\times 8 \mathrm{~mm}$, KNAUER, Germany) packed with Eurokat $\mathrm{H}, 10 \mu \mathrm{m}$.

The gas chromatograph (GC) used in this study was purchased from chromatographic specialties (SRI Instrument, Brockville, Canada). The GC is equipped with a flame ionized detector (FID). A Stabilwax column, $30 \mathrm{M} \times 53 \mathrm{MM}, 1 \mu \mathrm{m}$ w/5 M Integra-guard (Restek, purchased from Chromatography Specialties, Brockville, Canada) was used to analyse acetone, ethanol, butanol, acetic acid and butyric acid in model solutions and ABE fermentation broths. Nitrogen and zero air were used as the carrier gas and ignition gas for flame, respectively. The column temperature was $40^{\circ} \mathrm{C}$ when the samples were injected and this temperature was kept for 2 minutes and then increased to $200^{\circ} \mathrm{C}$ with the rate of $20^{\circ} \mathrm{C} / \mathrm{min}$. The injector and FID detector temperatures were $250^{\circ} \mathrm{C}$ and $110^{\circ} \mathrm{C}$, respectively.

\subsection{Fermentation Experiments}

The microorganism used in this study to produce butanol was Clostridium acetobutylicum ATCC 824 purchased from American Type Culture Collection (ATCC). The bacterium was stored at $4^{\circ} \mathrm{C}$ in the form of spores in Reinforced Clostridium Medium (RCM) purchased from Sigma-Aldrich Canada. To revive the bacteria, heat shock at $80^{\circ} \mathrm{C}$ for 10 minutes followed with cooling in ice for one minute was used. The revived bacteria were kept at $37^{\circ} \mathrm{C}$ in roller incubator for 48 hours. The revived bacteria were used to inoculate the fermenter. The fermentation media contained: yeast extract $(5 \mathrm{~g} / \mathrm{L}), \mathrm{KH}_{2} \mathrm{PO}_{4}$ and $\mathrm{K}_{2} \mathrm{HPO}_{4}(0.75 \mathrm{~g} / \mathrm{L}), \mathrm{NaCl}(1 \mathrm{~g} / \mathrm{L})$, $\mathrm{MgSO}_{4} \cdot 7 \mathrm{H}_{2} \mathrm{O}(0.2 \mathrm{~g} / \mathrm{L}), \mathrm{MnSO}_{4} \cdot \mathrm{H}_{2} \mathrm{O}$ and $\mathrm{FeSO}_{4} \cdot 7 \mathrm{H}_{2} \mathrm{O}(0.01 \mathrm{~g} / \mathrm{L})$, L-cysteine $\mathrm{HCl}(0.5 \mathrm{~g} / \mathrm{L})$ and glucose (50 
$\mathrm{g} / \mathrm{L}$ ). The inoculed medium of $250 \mathrm{~mL}$ was used for each batch fermenter.

\subsection{Methods}

To quantify the concentrations of each component in ABE solutions, HPLC was used to separate as well as possible all components present in tested samples. The HPLC chromatogram includes different asymmetric Gaussian curves, one for each component. The area under each asymmetric Gaussian curve is related to the concentration of the components in the sample. To properly quantify each component of the fermentation broth, it is necessary to determine the underlying relationship relating the concentration and the area under the asymmetric Gaussian curve. This relationship, which is a linear and referred to as the standard calibration curve, was determined experimentally in the present study. However, due to the characteristics of components leading to similar retention times, some conflicts may occur between the different peaks in the HPLC chromatograms. For the peaks that are conflicting with each other, a computer program, written in MATLAB using an asymmetric Gaussian curve represented by Equation (1), was used to fit the raw data of each peak of the HPLC chromatogram. This equation was fitted to the experimental data either for completely separated peaks or for the overlapped peaks using an equation comprised of the summation of two or three asymmetric Gaussian curves with specific coefficients that were obtained by minimizing the sum of squares of the errors between the experimental and predicted data. In the program, the overlapped peaks were detected, the parameters of each asymmetric Gaussian curve were determined and, using the particular coefficients of the asymmetric Gaussian curve associated to each peak, the area underneath the curve was calculated. Then, using the standard calibration curve of each component, the concentration was estimated. The asymmetric Gaussian curve used in the program was:

$$
y=\left[\frac{a}{2 \times d} \exp \left(\frac{c^{2}}{2 \times d^{2}}+\frac{(b-t)}{d}\right) \operatorname{erf}\left(\frac{t-b}{\sqrt{2} \times c}-\frac{c}{\sqrt{2} \times d}+1\right)\right]
$$

where $\mathrm{y}$ is the voltage $(\mathrm{mV}), \mathrm{t}$ is the time $(\mathrm{min})$ and $\mathrm{a}, \mathrm{b}, \mathrm{c}$ and $\mathrm{d}$ are the parameters related to the area, retention time (RT), width and exponential damping terms of the peak. For the overlapped peaks, the summation of two or three asymmetric Gaussian curves (Equation (1)) was used. To calculate the area under each peak, the four model parameters (a, b, c and d) were determined for each peak (eight parameters for two and twelve parameters for three overlapped peaks).

\section{Results and Discussion}

\subsection{HPLC Optimum Operating Conditions}

To test the HPLC performance with the Vertex column, the first step was to test each component in a binary aqueous solution to determine the retention time (RT) of all components that will be present in the HPLC chromatogram. Since the retention time of a component depends on the mobile phase flow rate and the column temperature, different values of these two operating variables were tested to find the best operating conditions for the analysis of ABE model solutions. For ABE model solutions, the peaks of butyric acid, acetone and ethanol usually have partial conflicts or are totally overlapped. It is therefore important to find the optimum mobile phase flow rate and column temperature to have minimum conflict between the peaks of these three components. Different mobile phase flow rates $(0.3,0.4,0.5,0.8,0.9$ and $1 \mathrm{~mL} / \mathrm{min})$ and column temperatures $\left(65^{\circ} \mathrm{C}, 80^{\circ} \mathrm{C}\right.$, $85^{\circ} \mathrm{C}, 87^{\circ} \mathrm{C}, 90^{\circ} \mathrm{C}$ ) were tested to find the best operating conditions to perform this analysis. Figure 1 shows the results of these experiments. As it can be observed, at $65^{\circ} \mathrm{C}$ and $0.5 \mathrm{~mL} / \mathrm{min}$, there is major overlapping at elution time between 29 and 31 min (Figure 1(a)). Increasing the temperature to $80^{\circ} \mathrm{C}$ and decreasing the flow rate to $0.3 \mathrm{~mL} / \mathrm{min}$, although the three peaks were detected, the peaks were still overlapping with each other (Figure 1(b)) and similar results were observed at the same temperature for 0.5 and $0.8 \mathrm{~mL} / \mathrm{min}$ (Figure 1(c) and Figure 1(d)). Therefore, the flow rate was kept at $0.4 \mathrm{~mL} / \mathrm{min}$ and the temperature was increased to $85^{\circ} \mathrm{C}$ and still the first two peaks of those three components were not detected separately as two peaks (Figure 1(e)) so the flow rate was increased to $0.8 \mathrm{~mL} / \mathrm{min}$ at the same temperature and this time it was observed that the overlapped peaks could be detected with a higher resolution (Figure 1(f)). This was the best possible result since by increasing the flow rate to 0.9 or $1 \mathrm{~mL} / \mathrm{min}$ or the temperature to $90^{\circ} \mathrm{C}$, the conflicts between the peaks increased (Figure $1(\mathrm{~g})$ and Figure 1(h)). Thus the optimum operating conditions for HPLC was selected to be at a flow rate of $0.8 \mathrm{~mL} / \mathrm{min}$ and $85^{\circ} \mathrm{C}$ as the column temperature. 


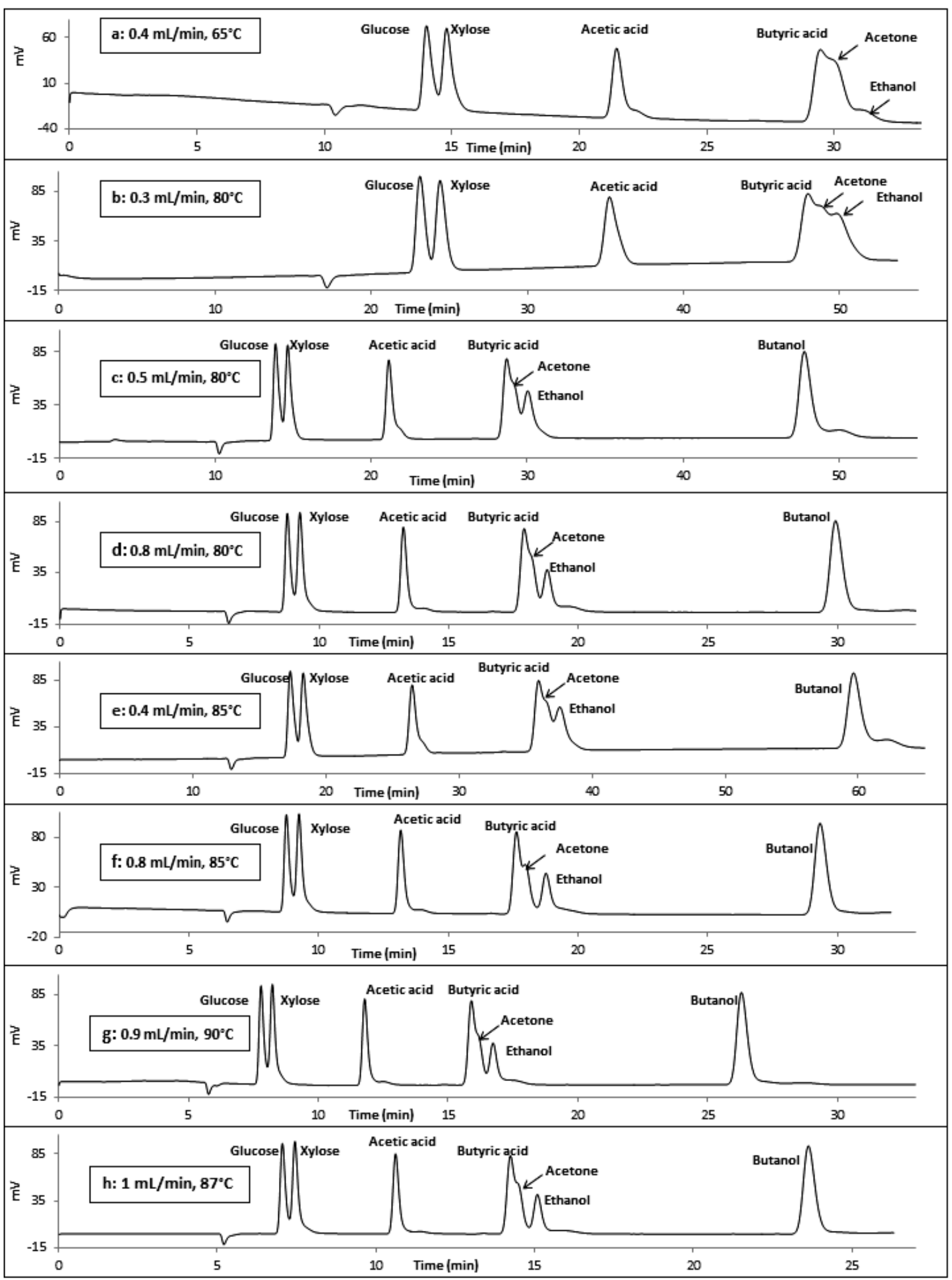

Figure 1. HPLC chromatograms at (a) $0.5 \mathrm{~mL} / \mathrm{min}, 65^{\circ} \mathrm{C}$; (b) $0.3 \mathrm{~mL} / \mathrm{min}, 80^{\circ} \mathrm{C}$; (c) $0.5 \mathrm{~mL} / \mathrm{min}, 80^{\circ} \mathrm{C}$; (d) $0.8 \mathrm{~mL} / \mathrm{min}$, $80^{\circ} \mathrm{C}$; (e) $0.4 \mathrm{~mL} / \mathrm{min}, 85^{\circ} \mathrm{C}$; (f) $0.8 \mathrm{~mL} / \mathrm{min}, 85^{\circ} \mathrm{C}$; (g) $0.9 \mathrm{~mL} / \mathrm{min}, 90^{\circ} \mathrm{C}$; (h) $1 \mathrm{~mL} / \mathrm{min}, 87^{\circ} \mathrm{C}$. 


\subsection{Standard Solution Analysis}

Standard solutions were prepared at different concentrations $(0.5,1,5,10,15$ and $20 \mathrm{~g} / \mathrm{L})$ to obtain both the RT of each component as well as to determine the area of the peaks at different known concentrations. The results showed that all components were eluted in the following order in increasing RT: glucose, xylose, acetic acid, butyric acid, acetone, ethanol and butanol. The retention times for all components are shown in Table 1. It was confirmed that the peaks with conflicts are butyric acid, acetone and ethanol having very close retention times. It was also observed that glucose and xylose peaks have also partial overlaps.

Using these results (peak areas and the corresponding concentrations), standard calibration curves for each component were plotted separately. Figure 2 shows the standard curves estimated using both the results of the HPLC software and the computer program. In each graph, the HPLC raw data (voltage vs time) were analyzed with both the HPLC software (Breeze) and the computer program to calculate the area of the peaks. Using regression with both slope and intercept errors, standard calibration curves were plotted and the equations relating the peak area $(\mathrm{mV} \times \mathrm{s})$ to the component concentration $(\mathrm{g} / \mathrm{L})$ were obtained. Table 1 shows the retention times, the standard calibration equations, and the coefficients of determination of the different compounds obtained by both the HPLC software and the proposed method. Two or three repeats were performed for each experiment and the average value was used to obtain the regression equation (Table 1). Slight differences in the slope of the standard calibration curves obtained by HPLC and the computer program were observed and this might be due to the small bumps after each asymmetric Gaussian peak in HPLC chromatograms that are considered. HPLC software considers these bumps in the area calculation whereas, in the computer program these tailings, were neglected.

\subsection{Standard Calibration Curve Validation}

The next step was to validate the standard calibration curves using test samples with known concentrations of each compound. Two binary aqueous solutions of $10 \mathrm{~g} / \mathrm{L}$ of each component were prepared and the HPLC raw data were used to calculate the area of the peaks and the concentrations using both the HPLC software and the MATLAB program. Table 2 shows the results of this comparison. As it can be observed, the concentrations estimated by the computer program are very similar to the ones calculated by the HPLC software and even closer to the concentrations of the test solutions. The standard error of the estimate for using the HPLC and proposed computer program was 0.44 and 0.19 , respectively. Thus, the results confirmed that the standard calibration curves, calculated using the MATLAB program, were more accurate.

\subsection{Validation of the Method}

To validate the proposed method based on the HPLC performance, the limit of detection (LOD), limit of quantification (LOQ), repeatability, intermediate precision and reproducibility were considered [25] [26]. Five different solutions with different concentrations between 0.5 and $20 \mathrm{~g} / \mathrm{L}(0.5-30 \mathrm{~g} / \mathrm{L}$ for butanol) were prepared for each component to determine the LOD and LOQ. 3 and 10 were the signal to noise ratio considered for these parameters. The LODs were $0.29,0.4,0.12,0.27,0.15$ and $0.07 \mathrm{~g} / \mathrm{L}$ for butanol, acetone, ethanol, butyric acid,

Table 1. The standard calibration curves and retention times of ABE solution components in HPLC chromatograms. A is the area $(\mu \mathrm{V} \times \mathrm{s})$ of the peak for each component.

\begin{tabular}{cccccc}
\hline Component & $\begin{array}{c}\text { Retention } \\
\text { time }(\mathrm{min})\end{array}$ & Concentration $(\mathrm{g} / \mathrm{L})$ & $\begin{array}{c}\text { Coefficient of } \\
\text { determination }\left(\mathrm{R}^{2}\right)\end{array}$ & $\begin{array}{c}\text { Regression equation } \\
\text { using MATLAB program }\end{array}$ & $\begin{array}{c}\text { Coefficient of } \\
\text { determination }\left(\mathrm{R}^{2}\right)\end{array}$ \\
\hline Glucose & $8.6-8.7$ & $3.1 \times 10^{-6} \mathrm{~A}-0.001$ & 0.9999 & $3.4 \times 10^{-6} \mathrm{~A}-0.033$ & 1.0000 \\
Xylose & $9.1-9.3$ & $3.2 \times 10^{-6} \mathrm{~A}+0.010$ & 0.9999 & $3.5 \times 10^{-6} \mathrm{~A}-0.018$ & 1.0000 \\
Acetic acid & $13.0-13.3$ & $6.7 \times 10^{-6} \mathrm{~A}+0.224$ & 0.9989 & $7.4 \times 10^{-6} \mathrm{~A}+0.041$ & 0.9998 \\
Butyric acid & $17.7-17.8$ & $5.5 \times 10^{-6} \mathrm{~A}+0.064$ & 0.9998 & $5.6 \times 10^{-6} \mathrm{~A}+0.082$ & 0.9999 \\
Acetone & $17.9-18.2$ & $9.7 \times 10^{-6} \mathrm{~A}+0.162$ & 0.9991 & $1.0 \times 10^{-5} \mathrm{~A}+0.019$ & 0.9998 \\
Ethanol & $18.6-18.9$ & $1.0 \times 10^{-5} \mathrm{~A}+0.259$ & 0.9973 & $1.1 \times 10^{-5} \mathrm{~A}-0.055$ & 1.0000 \\
Butanol & $29.4-29.9$ & $6.2 \times 10^{-6} \mathrm{~A}-0.001$ & 0.9993 & $6.5 \times 10^{-6} \mathrm{~A}-0.069$ & 0.9999 \\
\hline
\end{tabular}




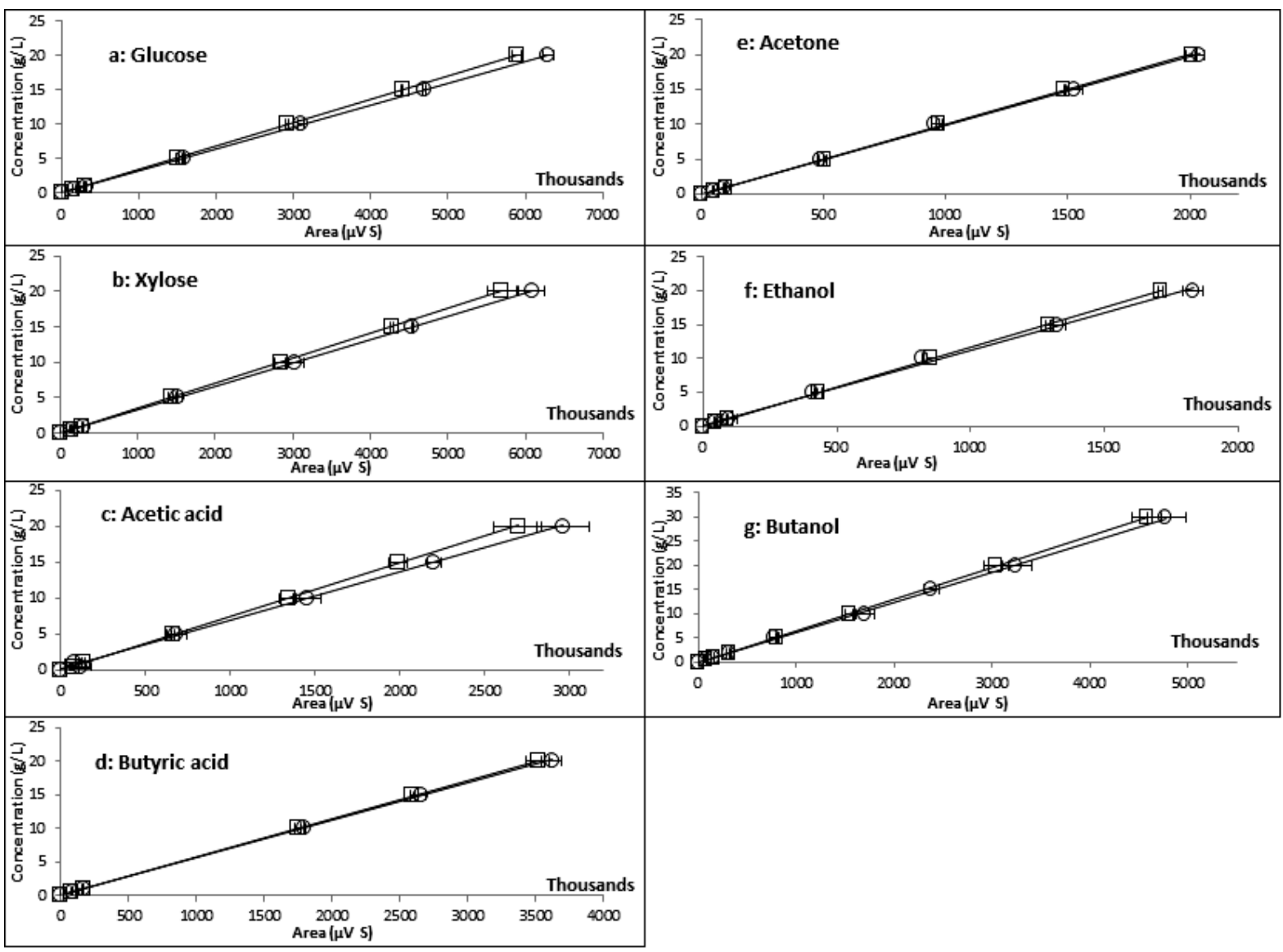

Figure 2. The standard calibration curves for (a) Glucose; (b) Xylose; (c) Acetic acid; (d) Butyric acid; (e) Acetone; (f) Ethanol; (g) Butanol. Standard calibration curves: MATLAB program ( $\square$ ) and HPLC software (O).

Table 2. Results of HPLC and the computer program for $10 \mathrm{~g} / \mathrm{L}$ aqueous binary solutions of glucose, xylose, acetic acid, butyric acid, acetone, ethanol and butanol.

\begin{tabular}{ccccc}
\hline & \multicolumn{2}{c}{ HPLC program } & \multicolumn{2}{c}{ Proposed computer program } \\
\hline Component & Solution 1 & Solution 2 & $9.88 \pm 0.12$ & Solution 2 \\
\hline Glucose & $9.76 \pm 0.16$ & $9.94 \pm 0.16$ & $9.79 \pm 0.32$ & $10.21 \pm 0.12$ \\
Xylose & $9.70 \pm 0.30$ & $10.25 \pm 0.31$ & $9.71 \pm 0.45$ & $10.22 \pm 0.47$ \\
Acetic acid & $9.55 \pm 0.51$ & $10.33 \pm 0.53$ & $9.89 \pm 0.27$ & $10.08 \pm 0.28$ \\
Butyric acid & $10.04 \pm 0.33$ & $9.97 \pm 0.32$ & $9.85 \pm 0.23$ & $9.67 \pm 0.22$ \\
Acetone & $9.63 \pm 0.17$ & $9.42 \pm 0.39$ & $10.10 \pm 0.09$ & $9.81 \pm 0.09$ \\
Ethanol & $9.26 \pm 0.64$ & $9.26 \pm 0.64$ & $9.82 \pm 0.40$ & $9.93 \pm 0.40$ \\
Butanol & $10.26 \pm 0.53$ & $10.40 \pm 0.54$ & &
\end{tabular}

acetic acid, glucose and xylose, respectively. The LOQ calculated for butanol, acetone, ethanol, butyric acid, acetic acid, glucose and xylose were $0.96,1.35,0.42,0.95,0.9,0.52$ and $0.23 \mathrm{~g} / \mathrm{L}$, respectively. The ranges of LOD and LOQ showed that HPLC has the adequate sensitivity toward the components present in the ABE fermentation broths.

Repeatability, intermediate precision and reproducibility were determined based on three different sets of samples. To determine the repeatability, the samples were analysed in the same day and the time between the samples analysis was short. To determine the intermediate precision of the proposed program, samples were analysed in different days to have a few days gap between each sample. And to determine the reproducibility, the samples were analysed using a different set of standard curves (the standard curves obtained by HPLC soft- 
ware). Both area and the retention time of each component (six samples with same concentration) were considered to evaluate the repeatability, intermediate precision and reproducibility. The results (Table 3) showed that for the retention time the repeatability, intermediate precision and reproducibility were less than $0.99 \%, 0.93 \%$ and $1.4 \%$ (coefficient of variation (CV) value), respectively. These values changed to 3.96\%, 3.66\% and 3.24\% for the repeatability, intermediate precision and reproducibility for the peak are, respectively. Therefore, these $\mathrm{CV}$ values confirmed that the HPLC operation is pretty accurate and the proposed method using the computer program can be used to analyse the ABE fermentation broth samples.

To be able to use the computer program to separate the overlapped peaks in multi component solutions it was necessary to ensure that the peaks were not correlated. This implies that changing the concentration of one component does not affect the peaks of other components, especially for the peaks that are overlapping. To study the characteristics of the overlapped peaks (butyric acid, acetone and ethanol) in order to track the changes of peak shapes in different cases, a series of experiments were performed using model solutions containing all seven components. In these experiments, the concentrations of two of the three components with overlapped peaks were kept constant and the concentration of the third component was changed to observe the changes of the peaks for the concentration of the other two compounds. The results showed that the peaks are not correlated and changes in each peak are independent of the other overlapped peaks. Results of this analysis are shown in Table 4. Similar experiments were performed to test the computer program for quantifying the glucose and xylose peaks. Results showed that these two peaks are also not correlated and the changes in the concentration of each component do not affect the peaks of other components (Table 5).

Figure 3 also shows the overlapped peaks of HPLC chromatogram for the components (butyric acid-acetoneethanol and glucose-xylose) that are conflicting. The dotted lines represent the data from HPLC program and the lines with light color is the asymmetric Gaussian curves, fitted to the overlapped peaks and the lines with dark color shows the peaks separated from the overlapped peaks, plotted with the determined coefficients estimated by the computer program (Figure 3).

As the final step, three different ABE model solutions with approximately the same concentrations were prepared and the data of the HPLC chromatograph were used to validate the estimates obtained with the computer program. Table 6 shows the results of the analysis obtained using the computer program to calculate the concentrations of all seven components present in the ABE model solutions.

Solutions with known concentrations of butanol, acetone, ethanol, acetic acid and butyric (around $4 \mathrm{~g} / \mathrm{L}$ of each)were also prepared to compare the analysis of the same sample with GC and the HPLC. The concentrations obtained by the GC were 3.9, 3.98, 3.96, 4.3 and $4.13 \mathrm{~g} / \mathrm{L}$ for acetone, ethanol, butanol, acetic acid and butyric acid, respectively. The same sample was injected to HPLC and the concentration detected for acetone, ethanol, butanol, acetic acid and butyric acid were 3.98, 4.1, 4.03, 4.5 and 4.16, respectively.

Finally the real fermentation broth was used to test the proposed method and the concentrations obtained for acetone, ethanol, butanol, acetic acid and butyric acid were obtained as 5.37, 0.55, 10.1, 0.6 and $0.2 \mathrm{~g} / \mathrm{L}$, respectively. These results were validated with GC analysis and the concentrations of acetone, ethanol, butanol, acetic acid and butyric acid were 5.15, 0.8, 9.6, 0.68 and 0.09 , respectively.

Table 3. Repeatability, intermediate precision and reproducibility of the proposed method for all components present in ABE broths in term of coefficient of variation (CV) for retention time and peak area.

\begin{tabular}{|c|c|c|c|c|c|c|}
\hline \multirow{2}{*}{ Components } & \multicolumn{2}{|c|}{$\begin{array}{l}\text { Repeatability } \\
\qquad(\mathrm{n}=6)\end{array}$} & \multicolumn{2}{|c|}{$\begin{array}{l}\text { Intermediate precision } \\
\qquad(\mathrm{n}=6)\end{array}$} & \multicolumn{2}{|c|}{$\begin{array}{l}\text { Reproducibility } \\
\qquad(\mathrm{n}=6)\end{array}$} \\
\hline & $\begin{array}{l}\text { Retention time } \\
\text { (CV\%) }\end{array}$ & $\begin{array}{l}\text { Peak area } \\
(\mathrm{CV} \%)\end{array}$ & $\begin{array}{l}\text { Retention time } \\
\text { (CV\%) }\end{array}$ & $\begin{array}{l}\text { Peak area } \\
(\mathrm{CV} \%)\end{array}$ & $\begin{array}{l}\text { Retention time } \\
\text { (CV\%) }\end{array}$ & $\begin{array}{c}\text { Peak area } \\
(\mathrm{CV} \%)\end{array}$ \\
\hline Glucose & 0.55 & 1.48 & 0.8 & 3.14 & 1.4 & 2.83 \\
\hline Xylose & 0.99 & 2.84 & 0.93 & 3.66 & 1.28 & 3.49 \\
\hline Acetic acid & 0.73 & 1.17 & 0.55 & 0.87 & 0.44 & 0.91 \\
\hline Butyric acid & 0.38 & 1.97 & 0.29 & 2.16 & 0.31 & 2.45 \\
\hline Acetone & 0.26 & 3.96 & 0.16 & 3.62 & 0.17 & 3.24 \\
\hline Ethanol & 0.22 & 2.88 & 0.29 & 2.07 & 0.29 & 2.39 \\
\hline Butanol & 0.91 & 0.55 & 0.52 & 0.65 & 0.77 & 0.38 \\
\hline
\end{tabular}


Table 4. Concentrations of the solutions used for the validation of Equation (1) using different combinations of concentrations for butyric acid, acetone and ethanol.

\begin{tabular}{ccccc}
\hline & Reference solution & Lower butyric acid conc. & Lower acetone conc. & Lower ethanol conc. \\
\hline Butyric acid $(\mathrm{g} / \mathrm{L})$ & $7.47 \pm 0.23$ & $3.30 \pm 0.14$ & $6.98 \pm 0.22$ & $6.79 \pm 0.21$ \\
Acetone $(\mathrm{g} / \mathrm{L})$ & $13.83 \pm 0.28$ & $13.64 \pm 0.28$ & $10.74 \pm 0.25$ & $13.45 \pm 0.31$ \\
Ethanol $(\mathrm{g} / \mathrm{L})$ & $12.61 \pm 0.11$ & $12.87 \pm 0.11$ & $12.91 \pm 0.11$ & $8.30 \pm 0.07$ \\
\hline
\end{tabular}

Table 5. Concentrations of the solutions used for the validation of Equation (1) using different combinations of concentrations for glucose and xylose.

\begin{tabular}{cccc}
\hline & Reference solution & Lower glucose conc. & Lower xylose conc. \\
\hline Glucose $(\mathrm{g} / \mathrm{L})$ & $4.98 \pm 0.08$ & $2.63 \pm 0.06$ & $5.29 \pm 0.09$ \\
Xylose $(\mathrm{g} / \mathrm{L})$ & $5.14 \pm 0.20$ & $5.15 \pm 0.20$ & $2.64 \pm 0.14$ \\
\hline
\end{tabular}

Table 6. Results obtained using the computer program to calculate the concentration of all components in ABE model solutions comprised of glucose: 4 g/L, xylose: 4 g/L, acetic acid: 5 g/L, butyric acid: 5 g/L, acetone: 6 g/L, ethanol: 2 g/L and butanol $12 \mathrm{~g} / \mathrm{L}$.

\begin{tabular}{cccc}
\hline & & Concentration calculated by the program (g/L) & Solution 3 \\
\hline Glucose & Solution 1 & Solution 2 & $3.97 \pm 0.07$ \\
Xylose & $4.20 \pm 0.08$ & $4.29 \pm 0.08$ & $4.14 \pm 0.018$ \\
Acetic acid & $4.21 \pm 0.18$ & $4.22 \pm 0.18$ & $4.99 \pm 0.027$ \\
Butyric acid & $5.13 \pm 0.27$ & $5.24 \pm 0.28$ & $4.21 \pm 0.16$ \\
Acetone & $3.76 \pm 0.16$ & $3.83 \pm 0.15$ & $6.99 \pm 0.2$ \\
Ethanol & $6.5 \pm 0.21$ & $6.32 \pm 0.21$ & $2.56 \pm 0.05$ \\
Butanol & $2.00 \pm 0.06$ & $2.93 \pm 0.06$ & $12.17 \pm 0.47$ \\
\hline
\end{tabular}

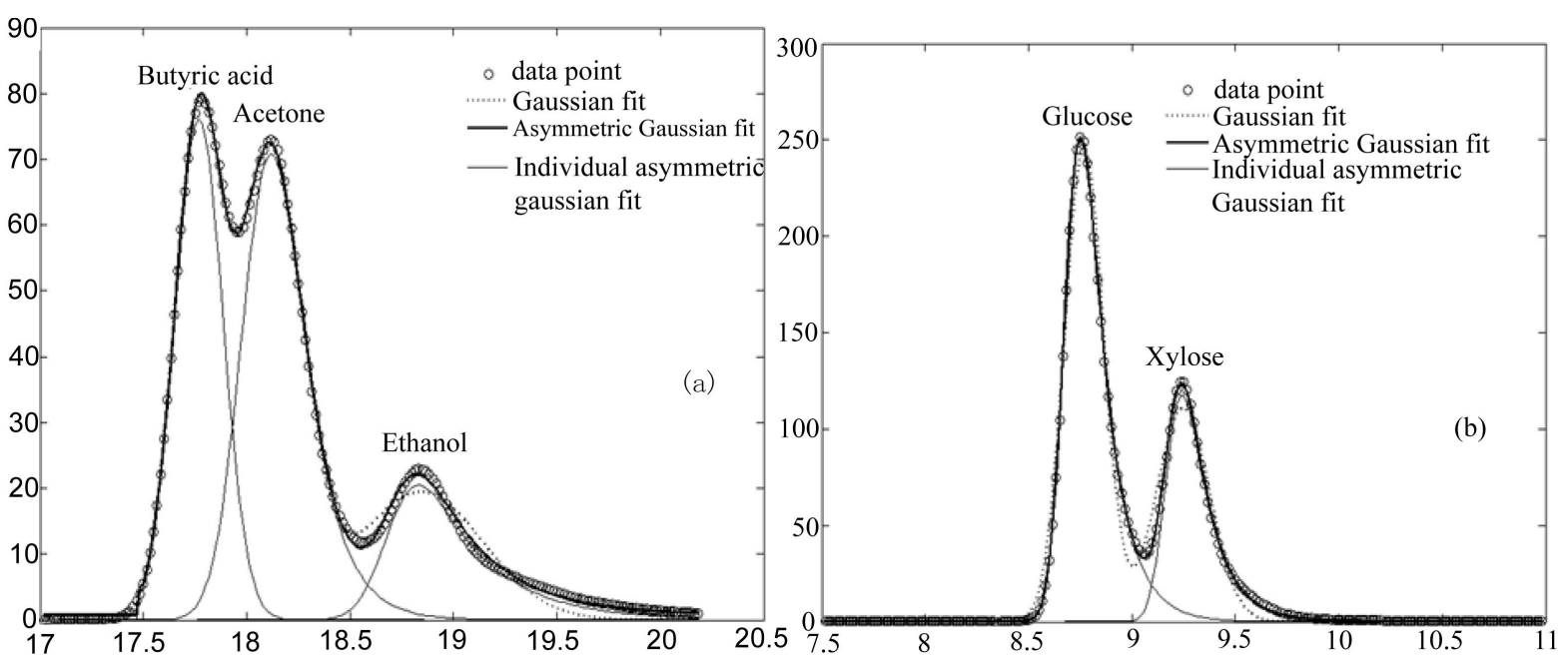

Figure 3. HPLC chromatograms for (a) butyric acid-acetone-ethanol and (b) glucose-xylose. The dotted lines are the HPLC raw data, and the lines are the fitted curves to the experimental data.

Results of this study showed that the computer program is able to deconvolute overlapping component peaks and to provide accurate estimates of the concentrations of the ABE components in a model solution. However, there are still some issues that remain to be investigated to develop a more accurate and precise program. One of the issues is the tailing of the peaks which is related to the mechanism of component separation in the HPLC column. Each component has a specific adsorption-desorption mechanism based on the HPLC column packing material and this mechanism determines the retention time of that specific component. When two or three com- 
ponents have similar or close retention times, they move together very closely along the column and this affects the shape of their peaks in the final chromatogram. Thus, although it is possible to deconvolute the peaks, each peak has a different shape than the one for pure components due to interactions between different components. This phenomenon will cause errors in the results of peak de convolution and the precision of the final concentration as measured by the computer program, will certainly be affected. However, in the ranges tested in the present study, the errors were not significant but it is still recommended to perform a more comprehensive investigation to develop an integrated program to obtain more accurate and precise results.

\section{Conclusion}

A method has been developed to better analyze the overlapping peaks in ABE solutions using HPLC. Due to very similar retention times of butyric acid, acetone and ethanol and also the close retention times of sugars (glucose and xylose) present in ABE fermentation broths, there are several peaks with conflicts in the HPLC chromatograms. This poses a significant challenge to determine the area of each peak and to quantify the corresponding concentrations. In this study, optimum operating conditions for the Vertex column, Eurokat $\mathrm{H}(300 \times$ $8 \mathrm{~mm}$, KNAUER, Germany) were found for ABE solution analysis (mobile phase flow rate of $0.8 \mathrm{~mL} / \mathrm{min}$ and the column temperature of $85^{\circ} \mathrm{C}$ ) to ensure that the peaks have minimum conflicts. Using asymmetric Gaussian curves, according to the characteristics of the peaks (being additive and not correlated) and linear regression in plotting the standard calibration curves, a program was written to fit the raw data from HPLC chromatograms to asymmetric Gaussian equations. Achieving an excellent fit, the program was able to determine the coefficients of the equations of each peak separately and to calculate the area of the curve. The standard calibration curves were validated by testing different samples of the components in binary and multi component aqueous solutions with known concentrations. Results show that this method is fairly accurate for ABE solution analysis but still needs some improvements to address some issues such as considering the different shapes of tailings of the peaks in order to make the program even more precise.

\section{Acknowledgements}

The authors would like to thank the University of Ottawa and the Natural Sciences and Engineering Research Council of Canada (NSERC) for their financial contributions for this study.

\section{References}

[1] Abdehagh, N., Tezel, F.H. and Thibault, J. (2014) Separation Techniques in Butanol Production: Challenges and Developments (Review). Biomass and Bioenergy, 60, 222-246. http://dx.doi.org/10.1016/j.biombioe.2013.10.003

[2] Abdehagh, N., Tezel, F.H. and Thibault, J. (2013) Adsorbent Screening for Biobutanol Separation by Adsorption: Kinetics, Isotherms and Competitive Effect of Other Compounds. Adsorption, 19, 1263-1272. http://dx.doi.org/10.1007/s10450-013-9566-8

[3] Thompson, A.B., Cope, S.J., Swift, T.D. and Notestein, J.M. (2011) Adsorption of n-Butanol from Dilute Aqueous Solution with Grafted Calixarenes. Langmuir, 27, 11990-11998. http://dx.doi.org/10.1021/la202508q

[4] Harvey, B.G. and Meylemans, H.A. (2011) The Role of Butanol in the Development of Sustainable Fuel Technologies. Journal of Chemical Technology \& Biotechnology, 86, 2-9. http://dx.doi.org/10.1002/jctb.2540

[5] Dellomonaco, C., Fava, F. and Gonzalez, R. (2010) The Path to Next Generation Biofuels: Successes and Challenges in the Era of Synthetic Biology. Microbial Cell Factories, 9, 3-17. http://dx.doi.org/10.1186/1475-2859-9-3

[6] Dürre, P. (2007) Biobutanol: An Attractive Biofuel. Biotechnology Journal, 2, 1525-1534. http://dx.doi.org/10.1002/biot.200700168

[7] Antoni, D., Zverlov, V.V. and Schwarz, W.H. (2007) Biofuels from Microbes (Mini Review). Applied Microbiology and Biotechnology, 77, 23-35. http://dx.doi.org/10.1007/s00253-007-1163-X

[8] Qureshi, N., Hughes, S., Maddox, I.S. and Cotta, M.A. (2005) Energy-Efficient Recovery of Butanol from Model Solutions and Fermentation Broth by Adsorption. Bioprocess and Biosystems Engineering, 27, 215-222. http://dx.doi.org/10.1007/s00449-005-0402-8

[9] Ezeji, T.C., Qureshi, N. and Blaschek, H.P. (2004) Butanol Fermentation Research: Upstream and Downstream Manipulations. Chemical Record, 4, 305-314. http://dx.doi.org/10.1002/tcr.20023

[10] Thirmal, C. and Dahman, Y. (2012) Comparison of Existing Pretreatment, Saccharification, and Fermentation Processes for Butanol Production from Agricultural Residues. Canadian Journal of Chemical Engineering, 90, 745-761. 
http://dx.doi.org/10.1002/cjce.20601

[11] Zheng, Y.N., Li, L.Z., Xian, M., Ma, Y.J., Yang, J.M., Xu, X. and He, D.Z. (2009) Problems with the Microbial Production of Butanol. Journal of Industrial Microbiology and Biotechnology, 36, 1127-1138. http://dx.doi.org/10.1007/s10295-009-0609-9

[12] Wu, Y.D., Xue, C., Chen, L.J. and Bai, F.W. (2013) Effect of Zinc Supplementation on Acetone-Butanol-Ethanol Fermentation by Clostridium acetobutylicum. Journal of Biotechnology, 165, 18-21. http://dx.doi.org/10.1016/j.jbiotec.2013.02.009

[13] Lu, C., Zhao, J., Yang, S.T. and Wei, D. (2012) Fed-Batch Fermentation for $n$-Butanol Production from Cassava Bagasse Hydrolysate in a Fibrous Bed Bioreactor with Continuous Gas Stripping. Bioresource Technology, 104, $380-387$. http://dx.doi.org/10.1016/j.biortech.2011.10.089

[14] Sharma, P. and Chung, W.J. (2011) Synthesis of MEL Type Zeolite with Different Kinds of Morphology for the Recovery of 1-Butanol from Aqueous Solution. Desalination, 275, 172-180. http://dx.doi.org/10.1016/j.desal.2011.02.049

[15] Oudshoorn, A., van der Wielen, L.A.M. and Straathof, A.J.J. (2009) Adsorption Equilibria of Bio-Based Butanol Solutions Using Zeolite. Biochemical Engineering Journal, 48, 99-103. http://dx.doi.org/10.1016/j.bej.2009.08.014

[16] Yang, X., Tsai, G.J. and Tsao, G.T. (1994) Enhancement of in Situ Adsorption on the Acetone-Butanol Fermentation by Clostridium acetobutylicum. Separations Technology, 4, 81-92. http://dx.doi.org/10.1016/0956-9618(94)80009-X

[17] Buday, Z., Linden, J.C. and Karim, M.N. (1990) Improved Acetone-Butanol-Ethanol Fermentation Analysis Using Subambient HPLC Column Temperature. Enzyme and Microbial Technology, 12, 24-27. http://dx.doi.org/10.1016/0141-0229(90)90175-P

[18] Wang, S., Zhang, Y., Dond, H., Mao, S., Zhu, Y., Wang, R., Luan, G. and Li, Y. (2011) Formic Acid Triggers the "Acid Crash" of Avetone-Butanol-Ethanol Fermentation by Clostridium acetobutylicum. Applied and Environmental Microbiology, 77, 1674-1680. http://dx.doi.org/10.1128/AEM.01835-10

[19] Finch, A.S., Mackie, T.D., Sund, C.J. and Sumner, J.J. (2011) Metabolite Analysis of Clostridium acetobutylicum: Fermentation in a Microbial Fuel Cell. Bioresource Technology, 102, 312-315. http://dx.doi.org/10.1016/j.biortech.2010.06.149

[20] Cho, D.H., Shin, S.J. and Kim, Y.H. (2012) Effects of Acetic Acid and Formic Acid on ABE Production by Clostridium acetobutylicum and Clostridium beijerinckii. Biotechnology and Bioprocess Engineering, 17, 270-275. http://dx.doi.org/10.1007/s12257-011-0498-4

[21] Kumar, M., Sainib, S. and Gayen, K. (2014) Acetone-Butanol-Ethanol Fermentation Analysis Using Only High Performance Liquid Chromatography. Analytical Methods, 6, 774-781. http://dx.doi.org/10.1039/c3ay41717d

[22] Matsumura, M., Takehara, S., and Kataoka, H. (1992) Continuous Butanol/Isopropanol Fermentation in Down-Flow Column Reactor Coupled with Pervaporation Using Supported Liquid Membrane. Biotechnology and Bioengineering, 39, 148-156.

[23] Setlhaku, M., Brunberg, S., Villa, E.A.V. and Wichmann, R. (2012) Improvement in the Bioreactor Specific Productivity by Coupling Continuous Reactor with Repeated Fed-Batch Reactor for Acetone-Butanol-Ethanol Production. Journal of Biotechnology, 161, 147-152. http://dx.doi.org/10.1016/j.jbiotec.2012.04.004

[24] Setlhaku, M., Heitmann, S., Górak, A. and Wichmann, R. (2013) Investigation of Gas Stripping and Pervaporation for Improved Feasibility of Two-Stage Butanol Production Process. Bioresource Technology, 136, 102-108. http://dx.doi.org/10.1016/j.biortech.2013.02.046

[25] Aranda-González, I., Moguel-Ordoñez, Y. and Betancur-Ancona, D. (2014) Rapid HPLC Method for Determination of Rebaudioside D in Leaves of Stevia rebaudiana Bertoni Grown in the Southeast of México. American Journal of Analytical Chemistry, 5, 813-819. http://dx.doi.org/10.4236/ajac.2014.513090

[26] Zhao, L., Liu, L. and Li, L. (2014) Qualitative and Quantitative Analysis of Five Bioactive Flavonoids in Salix bordensis Turcz. by HPLC-DAD and HPLC-ESI-MS. American Journal of Analytical Chemistry, 5, 851-860.

http://dx.doi.org/10.4236/ajac.2014.513094 


\section{List of Abbreviations}

ABE: Acetone-Butanol-Ethanol;

ATCC: American Type Culture Collection;

CV: Critical Value;

FID: Flame Ionized Detector;

GC: Gas Chromatograph;

HPLC: High Performance Liquid Chromatography;

LOD: Limit of Detection;

LOQ: Limit of Quantification;

NHOC: Net Heat of Combustion;

RCM: Reinforced Clostridium Medium;

RT: Retention Time. 
Scientific Research Publishing (SCIRP) is one of the largest Open Access journal publishers. It is currently publishing more than 200 open access, online, peer-reviewed journals covering a wide range of academic disciplines. SCIRP serves the worldwide academic communities and contributes to the progress and application of science with its publication.

Other selected journals from SCIRP are listed as below. Submit your manuscript to us via either submit@scirp.org or Online Submission Portal.
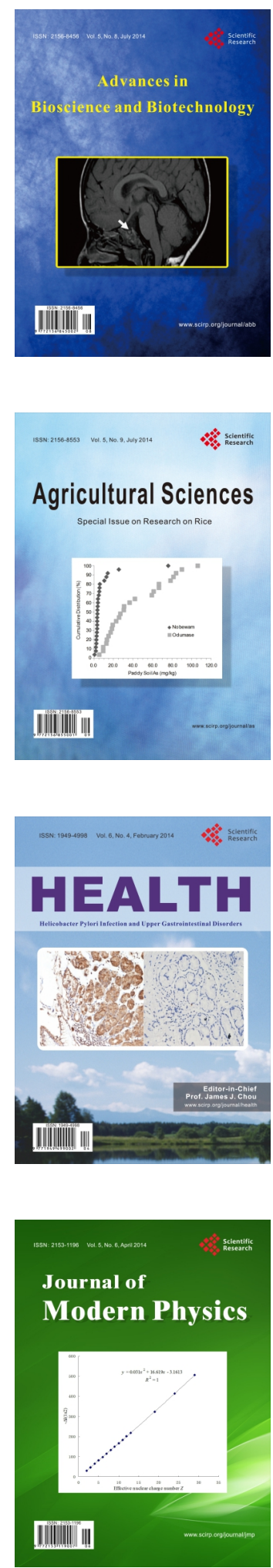
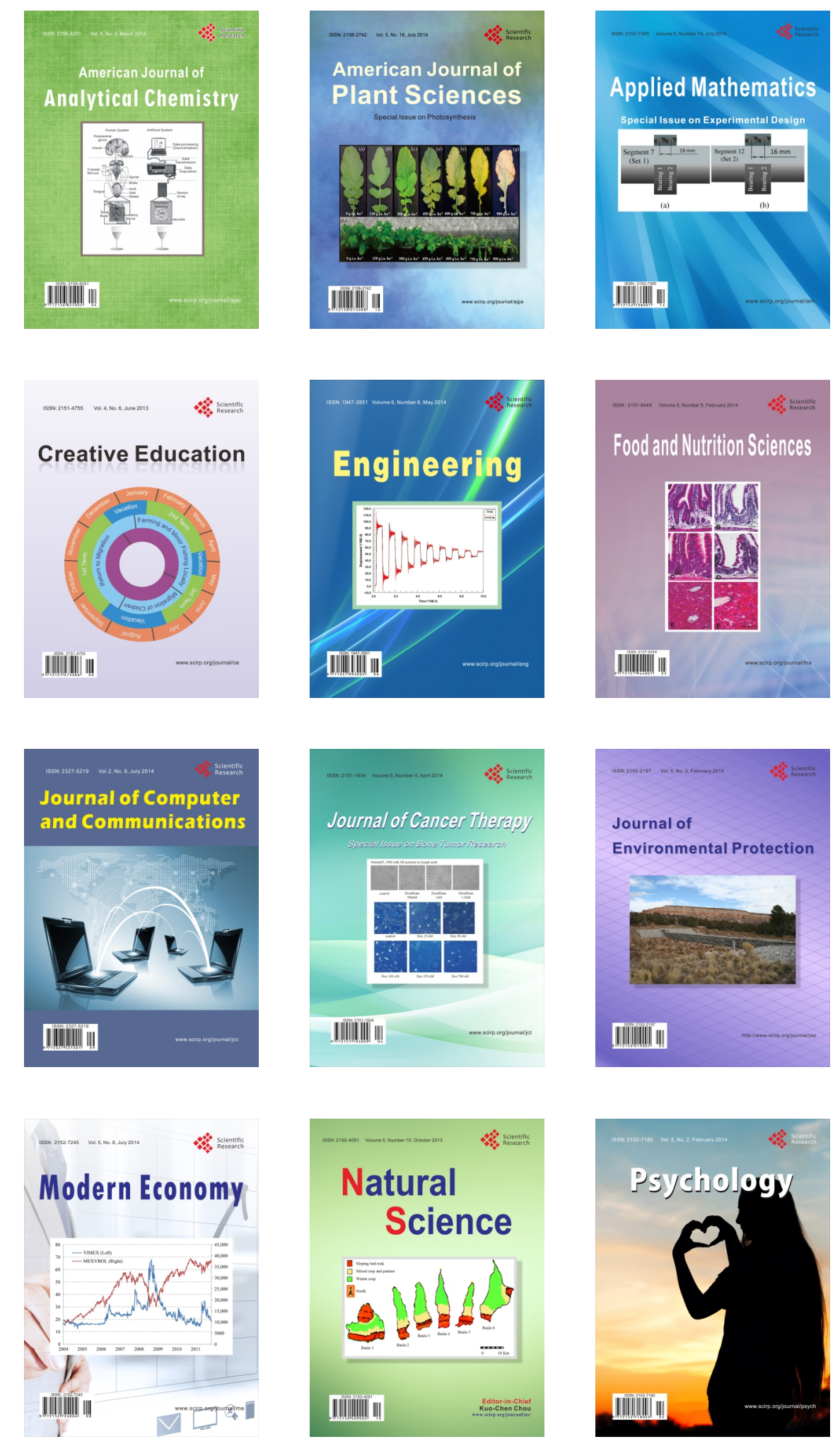